\title{
Research on Dynamic Capabilities and Innovation Performance in the Chinese Context: A Theory Model-Knowledge Based View
}

\author{
Yun Gao', Yongmei Zhu ${ }^{2}$ \\ ${ }^{1}$ School of Business Administration, South China University of Technology, Guangzhou, China \\ ${ }^{2}$ School of Mathematics, South China University of Technology, Guangzhou, China \\ Email: 63411359@163.com
}

Received 7 September 2015; accepted 9 October 2015; published 12 October 2015

Copyright (C 2015 by authors and Scientific Research Publishing Inc.

This work is licensed under the Creative Commons Attribution International License (CC BY). http://creativecommons.org/licenses/by/4.0/

\section{(c) (i) Open Access}

\begin{abstract}
To carry out contextualized research on theory of dynamic capabilities under the perspective of the knowledge-based, and explore the mechanism of international enterprises to enhance innovation performance in the Chinese context, also to build a theoretical model between "the Chinese context-dynamic capabilities-innovation performance", this study makes an attempt to theoretical research and management practices with combining the Chinese context. The study finds that building dynamic capability is the inevitable result of enterprises to survive and develop in the Chinese context, and it makes a contribution to knowledge transferring, sharing and creating in the international market, ultimately to enhance innovation performance, overcome latecomer disadvantages.
\end{abstract}

\section{Keywords}

Chinese Context, Dynamic Capabilities, Innovation Performance, Knowledge Based View

\section{Introduction}

In recent years, enterprises in emerging economies have joined the tide of internationalization, in order to obtain strategic resources and learning opportunities in the international market, also to enhance the innovation performance and overcome the weaknesses [1]. However, the existing research on the relationship between enterprise internationalization and innovation performance is based on the background of western developed countries, and 
there is no explanation to illustrate the mechanism of the interaction [2] [3]. In fact, the evolution of Chinese society has shaped a distinctive system of institution, market and cultural, which is different from the western society. The differences between Chinese and western context in cognitive basis, social trust and development conditions lead to a diverse sense of worth and strategic model, which are reasonable and long-term, and have a deep influence on the enterprises. However, the study in Chinese context is often ignored by scholars [4]-[6]. Therefore, this paper will conduct the research on the dynamic capability theory based on the knowledge perspective; explore the mechanism of enterprise internationalization process and innovation performance; and try to complement the research gap that the important role of Chinese context, also makes a useful attempt to provide a new perspective for studying of dynamic capacity theory.

\section{Theoretical Basis}

\subsection{Chinese Context}

Weber (2009) deemed that national context includes the material system and philosophy system, Child (2000) further proposed that national context constitute of national institution and culture. Li (2002) believes that Chinese context has double meanings. One is that China's unique institutional, legal and economic environment, the other is the dominant role of institutional context in China, which is leading the social, political and economic reform. This paper believes that the uniqueness of the Chinese context comes from the dual characteristics of Chinese economic transformation, the gradual, decentralization and experimental of embodiment, leading to the obvious institutional differences between different regions. In addition, has a long history of social culture is also an important manifestation of Chinese context, such as Confucianism and other traditional culture have a subtle influence on the management practices of Chinese enterprises. What's more, the unique phenomenon of Chinese management is more or less included in it, such as human relations and paternalistic leadership. Therefore, this paper considers that Chinese context is the result of the interaction between the special institutional environment and social culture, which has a significant effect on business operations [7].

\subsection{Dynamic Capabilities}

Dynamic capability is defined as "the ability of enterprise integration, construction and reorganization of internal and external resources to continuously adapt to the rapid changes in the environment" [8]. Most scholars emphasize that dynamic capability is the ability to integrate internal and external resources to adapt to the changes in environment, and the Higher-order ability to expand, change, or create conventional ability, determining the direction and speed of the change [9] [10]. In this paper, the evolution of dynamic capability and knowledge follows the path of "acquisition, transmission, integration and renewal", and finally, enterprises should integrate the knowledge to improve the organization routine, and promote the ability to improve the organization efficiency, in order to deal with the complex and changeable market environment and to obtain sustainable competitive advantage. In this paper, dynamic capability is divided into three dimensions: knowledge acquisition, knowledge creation and knowledge integration. Knowledge acquisition is the ability of enterprises to acquire new knowledge through external channels in order to perceive market opportunities and to make use of market changes. Knowledge creation is the ability of enterprises to create new knowledge through their own research and development. Knowledge integration is the ability of enterprise to effectively integrate the knowledge acquired from the external and internal creation to reconstruct the new knowledge.

\subsection{Innovation Performance}

The Party's eighteenth report proposed to implement the innovation driven development strategy to enhance the international competitiveness, and encourage Chinese enterprises to improve innovation ability in the process of internationalization, and even take the initiative to lead the market changes, shaping a strong business environment for their own development. Innovation is an important driving force to promote the development of the country, region and enterprise itself. It is the key to determine the survival and development of enterprises in the complex external environment, also is the most important problem in the field of innovation. Hagedoorn and Cloodt (2003) believe that the narrow sense of innovation performance refers to the process results of the enterprise to introduce into the market, and the broad sense of innovation performance refers to the market performance gaining from the entire process from the creative application to market. In this paper, the innovation per- 
formance is defined as the efficiency and effect of the enterprise through market innovation or technological innovation, and the ultimate goal is to improve the management efficiency and efficiency through innovation.

\section{The Formation Mechanism of Enterprise Dynamic Capabilities in Chinese Context}

The current domestic market environment is complex, the technology and product life cycle is shortened, and the economic growth and market mechanism is not perfect at all. Under this condition, the survival and development of Chinese enterprises not only to put forward higher requirements, but also to bring a lot of unique development opportunities. As the brutal competition in the nature, there is the same natural law of the survival of the fittest in the business ecosystem. The enterprise must adapt and lead the external environment changes to make itself in an invincible position, also establish dynamic capabilities to meet the needs of their survival and development in the fierce market competition [11].

\subsection{Knowledge Acquisition Capability}

Because of the special nature of economic transformation, China has not yet completed the transition to the market economy. The government still plays an important role in the economic operation and resource allocation under the planned economy and administrative intervention [12]. The complex situation of market segmentation makes the different regional markets present the characteristics of differentiation, and the enterprises need to acquire the knowledge from unified big market. More importantly, Chinese enterprises are facing a dilemma, such as "government oriented" or "market orientation", "market basis" or "resource base". The only way to make a suitable strategic choice is to possess enough knowledge base. Based on the characteristics of social culture, Chinese enterprises are more inclined to acquire knowledge and resources through the relationship network. In addition to building business relations to obtain market new demand, new technology and other information, Chinese enterprises have to establish a certain political relationship to obtain policy information, legitimacy and other special resources, to make up for the formal institution and the capital market imperfections caused by adverse effects [13] [14].

\subsection{Knowledge Creation Capability}

In the process of economic transformation, different ownership, different regions and different industries have been endowed with different social responsibility and institutional status. So enterprises in different institutions gain diverse preferential policies or protection policies, and the resources that be acquired through external channels are not the same. The resources of enterprise in lower institution are very limited. At this time, if enterprise wants to establish itself in the market, the optimal path is to create the necessary knowledge, in order to make up for the difference of institutions. Otherwise, enterprises with risk aversion can't break through the limitations of the traditional thinking, and actively respond to the inferior position. The only result is that the enterprises will be exhausted in the fierce market competition. More importantly, the enterprise has to obtain the tacit knowledge through operating in the market.

Absorptive capacity theory believes, the original resources and knowledge accumulation that enterprise had in the first place will affect the ability of identify, acquire and create the new one. Research shows that knowledge acquisition ability and creative ability have the effect of mutual promotion. On the one hand, the acquisition of external knowledge is the foundation and starting point of the internal knowledge creating, and it has the promotion effect. On the other hand, the knowledge base of enterprise has an important role in monitoring the external activities, which is helpful to identify and evaluate the value of external knowledge [15].

\subsection{Knowledge Integration Capability}

According to the theory of knowledge view, the integration capability is the key skill of the enterprise. Because of the complexity and variability of the external environment in Chinese context, enterprises need to build their own knowledge base through external and internal channels for survival and development. Therefore, it is not enough to obtain and create knowledge simply. The knowledge from different sources, different levels or different structure need to be chosen, absorbed, configured, merged [16]. The greatest value of knowledge only can be played after effective integration. Through the integration of non-exclusive mode can realize the maximiza- 
tion of the overall interests. Enterprises need to critically integrate the knowledge from external acquisition and interior creation, the new and old knowledge, and even the knowledge gained by different regional management practice. Take the essence, to its dregs, thus forming the enterprise knowledge to effectively guide enterprises to cope with environmental change and even lead it. Many theoretical and empirical studies have repeatedly demonstrated that the integration capability is the basis and core of the dynamic capabilities, is the key to gain and maintain the competitive advantage [17].

\section{Mechanism of Dynamic Capability in the Process of Internationalization}

Resource view theory and organizational learning theory believe that the implementation of the international strategy for emerging economies is to obtain strategic resources or learning opportunities, to overcome the weaknesses and achieve catch-up [1] [18]. But based on knowledge view, this paper considers that the essence of strategic resources or learning opportunities is for the acquisition, creation, storage, and application of knowledge [19]. Knowledge view theory believes, in the new era, enterprises can not only maintain the competitive advantage through the resource advantages. The transfer, sharing and creation of knowledge that be embedded in production processes, business models and leadership skills will help enterprise to obtain and maintain competitiveness, also to achieve superior performance. However, the knowledge and resources of enterprises have core rigidity and inertia. In addition, there are differences in the innovation activities of enterprises in different situations. Therefore, in the process of internationalization, enterprises need dynamic capabilities to realize survival and development, in order to improve innovation performance and maintain sustained core competitiveness [10].

\subsection{Knowledge Acquisition Capability and Innovation Performance}

Enterprise can't have all the necessary resources. Especially in the era of knowledge economy, enterprise can't simply rely on their own resources in the innovation to achieve self-sufficiency [20]. So learning international advanced knowledge and experience for the promotion of enterprise innovation is particularly important. The vast space of international market has brought more opportunities and challenges for Chinese enterprises. First of all, enterprises with higher knowledge acquisition ability have wider channel to obtain new demand, new technology, new ideas and other external information in the international market. Enterprises can grasp the trend of technological and market changes through understanding information into knowledge. Compared with competitors to more quickly perceive, identify and use the opportunity to establish a first mover advantage. Those enterprises can perceive, identify and take advantage of the opportunity more quickly, in order to establish the first mover advantage. But compared to developed countries, China's investment in innovation resources is significantly lower. The technology level is far lower than the developed countries, too. So, enterprises need to obtain complementary and key technology through the external channels when they find a new opportunity, such as technology transfer and patent licensing. In order to make up for the lack of knowledge basis, also overcome the bottleneck of resource constraints, and accelerate the process of innovation. However, the mature international market is more focused on acquiring knowledge and resources through market channels. For Chinese enterprises, which are used to obtain knowledge through the relationship network, the first task is learning how to overcome situational differences, and to integrate the international market more quickly and better.

\subsection{Knowledge Creation Capability and Innovation Performance}

Nowadays, Chinese enterprises are still in the inferior position of the bottom of the global economic chain. The lack of technology causes the enterprise to seek intellectual support from the outside. It is easy to fall into the trap like "backward-introduction-and then backward-and then introduce". The pursuit results in a vicious cycle. It is more difficult to improve the status of Chinese enterprises in the international market. In addition, the key knowledge of technological innovation is often considered as a strategic resource to be protected. Chinese enterprises can only obtain non-core technology or relatively backward technology through external channels, forced to follow the learning strategy. It is difficult to surpass or leading competitors. In particular, tacit knowledge such as experience skills and thinking patterns are important sources of enterprise innovation, but it is often difficult to obtain through external channels. The research shows, only 1/3 new knowledge that the enterprise innovation needs can be obtained from the outside, and the role of internal knowledge creation of technol- 
ogy for performance is much greater than external access [21]. Therefore, under the atmosphere of innovation in the international market, Chinese enterprises need to continuously improve the ability of knowledge innovation. Build the knowledge base of innovation and value creation through the key elements of innovation, such as technology, craftwork and creativity. On the one hand, knowledge creation capability can directly improve the innovation performance. On the other hand, it can make indirect effects on the innovation performance through the improvement of knowledge acquisition capability, and ultimately to achieve the strategic goal of catching up.

\subsection{Knowledge Integration Capability and Innovation Performance}

The construction of knowledge integration capability is the key to improve the innovation performance of Chinese enterprises. First of all, the management style of Chinese enterprises always depends on its history, and the practice process of organization will resist innovation partly. And the integration and reconstruction of resources can help the new knowledge from external acquisition and internal creation to spread and integrate with the existing knowledge in the enterprise effectively, enhancing the flexibility and coordination of resource [22]. Secondly, the knowledge required in international market innovative activities is often from different regions or industries, also throughout the process of manufacturing, design and marketing, etc. It requires business have ability to integrate knowledge in order to better understand and meet consumer demand, also adapt to and even lead the market change. Importantly, more knowledge resources don't mean better innovation performance. Only through effective integration and utilization can produce the synergy effect to play the biggest role in innovative activities of knowledge resources [23]. In particular, most of the emerging economies are faced with the plight of industry technology limitation. Therefore, the effective integration of external knowledge and local market knowledge is the most effective way. Such as the PHS mobile phone, which hadn't achieved technical innovation, but it firmly grasped the consumer for low income groups and received a decent income.

\subsection{Dynamic Capability and Innovation Performance}

In summary, by combining the three sub dimensions of dynamic capability, as knowledge acquisition, creation and integration capability, this paper constructs a model of the relationship among Chinese context, Dynamic Capabilities and Innovation Performance, as shown in Figure 1. To emphasize the important role of Chinese context, and expound the unique characteristics of Chinese context from the perspective of system and culture.

\section{Conclusions}

In this paper, we study dynamic capability theory based on knowledge view, and try to explore the formation mechanism of dynamic capability and its influence on innovation performance in the process of internationalization in theoretical level. The study find that, under the special institutional environment and social culture in Chinese context, enterprises must establish dynamic capabilities to cope with the complex and volatile external environment for the survival and development, otherwise it will be lost in the fierce market competition. There-

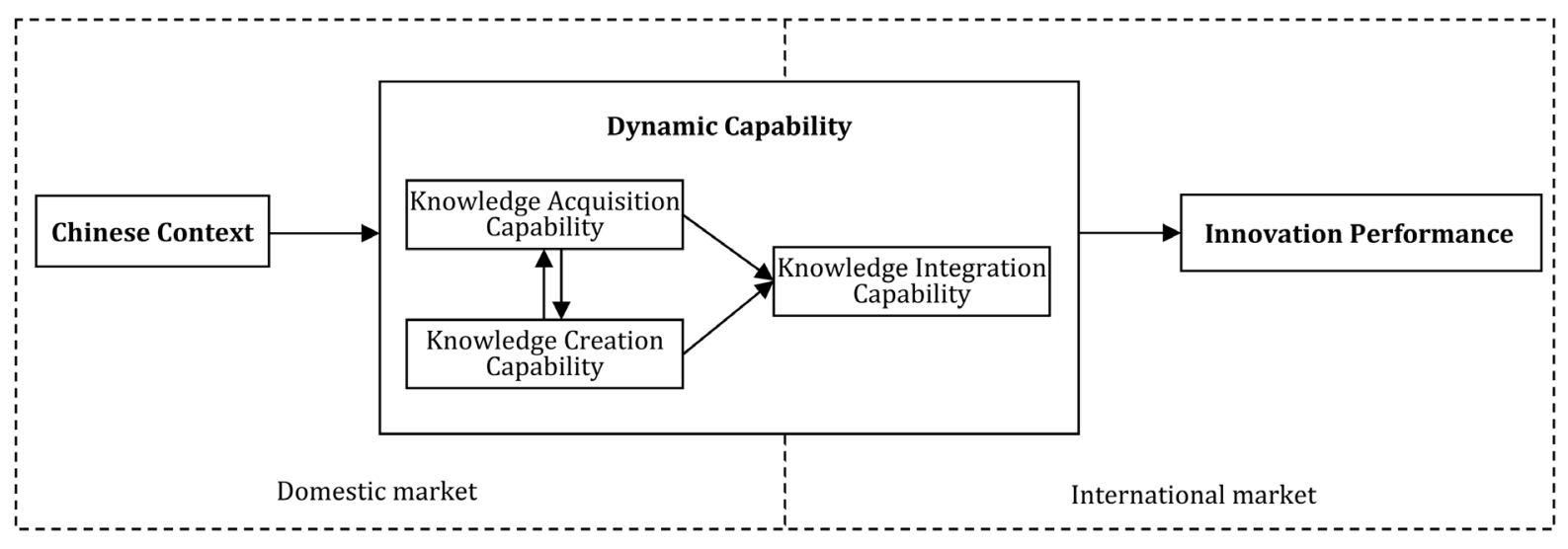

Figure 1. The researching framework among Chinese context, dynamic capabilities and innovation performance. 
fore, the three sub dimensions of dynamic capability, as knowledge acquisition, creation and integration capability, making an interaction to promote the Chinese enterprises to implement knowledge transfer, sharing and creation in the international market. Ultimately, it will enhance innovation performance, and overcome latecomer disadvantages.

This paper has important implications for the management of enterprises. First of all, the enterprise managers should take full account of the unique nature of Chinese context, facing the positive effect for institutional environment and social culture to the construction of dynamic capabilities, dynamic adaptation and even leading the market environment changes, dynamically adapting and even leading the market changes. Secondly, we should realize the key role of knowledge resources and integration ability in the knowledge economy era, achieve the knowledge transfer and innovation between parent and subsidiary company in the process of internationalization, and acquire the sustainable competitive advantage in the world. Finally, we should pay attention to the improvement of dynamic capabilities to match the enterprise strategy, and realize the value and maximize the benefits [24]. In the creation period, enterprise may obtain the knowledge that the enterprise management needs directly through technology transfer and patent license, in order to obtain the chance to live. But enterprises can't over rely on external resources acquisition. Otherwise, it will be un-conducive to the accumulation of internal resources, and be harmful to the further development of enterprises. When getting into the expansion stage, enterprises have enough knowledge base. Enterprises should focus on strengthening the construction of internal innovation mechanism, and also the integration capabilities, for the sake of further innovation performance.

\section{References}

[1] Kafouros, M.I., Buckley, P.J. and Sharp, J.A. (2008) The Role of Internationalization in Explaining Innovation Performance. Technovation, 28, 63-74. http://dx.doi.org/10.1016/j.technovation.2007.07.009

[2] Hijzen, A., Jean, S. and Mayer, T. (2011) The Effects at Home of Initiating Production Abroad: Evidence from Matched French Firms. Review of World Economics, 147, 457-483. http://dx.doi.org/10.1007/s10290-011-0094-X

[3] Navaretti, G.B., Castellani, D. and Disdier, A.C. (2010) How Does Investing in Cheap Labour Countries Affect Performance at Home? Firm-Level Evidence from France and Italy. Oxford Economic Papers, 62, 234-260. http://dx.doi.org/10.1093/oep/gpp010

[4] Lin, Z.J., Peng, M.W. and Yang, H. (2009) How Do Networks and Learning Drive M\&As? An Institutional Comparison between China and the United States. Strategic Management Journal, 30, 1113-1132. http://dx.doi.org/10.1002/smj.777

[5] Teece, D.J. (2014) A Dynamic Capabilities-Based Entrepreneurial Theory of the Multinational Enterprise. Journal of International Business Studies, 45, 8-37. http://dx.doi.org/10.1057/jibs.2013.54

[6] Wang, C.L. (2007) Dynamic Capabilities: A Review and Research Agenda. International Journal of Management Reviews, 9, 31-51. http://dx.doi.org/10.1111/j.1468-2370.2007.00201.x

[7] Tsui, A.S., Bian, Y.J. and Cheng, L. (2008) China’s Domestic Private Firms: Multidisciplinary Perspectives on Management and Performance. China Journal, 59, 212-214.

[8] Teece, D.J., Pisano, G. and Shuen, A. (1997) Dynamic Capabilities and Strategic Management. Strategic Management Journal, 18, 509-533. http://dx.doi.org/10.1002/(SICI)1097-0266(199708)18:7<509::AID-SMJ882>3.0.CO;2-Z

[9] Ambrosini, V., Bowman, C. and Collier, N. (2009) Dynamic Capabilities: An Exploration of How Firms Renew Their Resource Base. British Journal of Management, 20, 9-24. http://dx.doi.org/10.1111/j.1467-8551.2008.00610.x

[10] Elsenhardt, K.M. and Martin, J.A. (2000) Dynamic Capabilities: What Are They? Strategic Management Journal, 21, 1105-1121. http://dx.doi.org/10.1002/1097-0266(200010/11)21:10/11<1105::AID-SMJ133>3.0.CO;2-E

[11] Anwar, S.T. (2012) FDI Regimes, Investment Screening Process, and Institutional Frameworks: China versus Others in Global Business. Journal of World Trade, 46, 213-248.

[12] Bhaumik, S.K. and Dimova, R. (2014) Good and Bad Institutions: Is the Debate Over? Cross-Country Firm-Level Evidence from the Textile Industry. Cambridge Journal of Economics, 38, 109-126. http://dx.doi.org/10.1093/cje/bes089

[13] Sheng, S., Zhou, K.Z. and Li, J.J. (2011) The Effects of Business and Political Ties on Firm Performance: Evidence from China. Journal of Marketing, 75, 1-15. http://dx.doi.org/10.1509/jmkg.75.1.1

[14] Luo, Y., Huang, Y. and Wang, S.L. (2012) Guanxi and Organizational Performance: A Meta-Analysis. Management and Organization Review, 8, 139-172. http://dx.doi.org/10.1111/j.1740-8784.2011.00273.x

[15] Cohen, W.M. and Levinthal, D.A. (1990) Absorptive Capacity: A New Perspective on Learning and Innovation. Administrative Science Quarterly, 25, 128-152. http://dx.doi.org/10.2307/2393553 
[16] Sirmon, D.G., Hitt, M.A. and Ireland, R.D. (2007) Managing Firm Resources in Dynamic Environments to Create Value: Looking inside the Black Box. Academy of Management Review, 32, 273-292. http://dx.doi.org/10.5465/AMR.2007.23466005

[17] Flatten, T.C., Greve, G.I. and Brettel, M. (2011) Absorptive Capacity and Firm Performance in SMEs: The Mediating Influence of Strategic Alliances. European Management Review, 8, 137-152. http://dx.doi.org/10.1111/j.1740-4762.2011.01015.x

[18] Zhang, Y., Li, H. and Li, Y. (2010) FDI Spillovers in an Emerging Market: The Role of Foreign Firms' Country Origin Diversity and Domestic Firms’ Absorptive Capacity. Strategic Management Journal, 31, 969-989. http://dx.doi.org/10.1002/smj.856

[19] Spender, J.C. and Grant, R.M. (1996) Knowledge and the Firm: Overview. Strategic Management Journal, 17, 5-9. http://dx.doi.org/10.1002/smj.4250171103

[20] Kessler, E.H., Allocca, M.A. and Rahman, N. (2007) External Knowledge Accession and Innovation Speed in the Small and Medium Sized Enterprise (SME). Small Enterprise Research, 15, 1-21. http://dx.doi.org/10.1080/13215906.2007.11005829

[21] Carmen, H.M., Arias-Aranda, D. and Lloréns-Montes, F.J. (2007) The Impact of Absorptive Capacity on Technological Acquisitions Engineering Consulting Companies. Technovation, 27, 417-425. http://dx.doi.org/10.1016/j.technovation.2007.04.003

[22] Zhou, K.Z. and Wu, F. (2010) Technological Capability, Strategic Flexibility, and Product Innovation. Strategic Management Journal, 31, 547-561.

[23] Varis, M. and Littunen, H. (2010) Types of Innovation, Sources of Information and Performance in Entrepreneurial SMEs. European Journal of Innovation Management, 13, 128-154. http://dx.doi.org/10.1108/14601061011040221

[24] Teece, D.J. (2014) The Foundations of Enterprise Performance: Dynamic and Ordinary Capabilities in an (Economic) Theory of Firms. The Academy of Management Perspectives, 28, 328-352. http://dx.doi.org/10.5465/amp.2013.0116 